\title{
Correction to: Combining mutagenesis on Glu281 \\ of prenyltransferase NovQ and metabolic engineering strategies for the increased prenylated activity towards menadione
}

Wenfeng $\mathrm{Ni}^{1,2} \cdot$ Zhiming Zheng $^{1} \cdot$ Hui Liu ${ }^{1} \cdot$ Peng Wang ${ }^{1} \cdot$ Han Wang ${ }^{1,2} \cdot$ Xiaowen Sun $^{1,2} \cdot$ Qiang Yang $^{1,2}$. Zhiwei Fang $^{1,2} \cdot$ Hengfang Tang ${ }^{1,2} \cdot$ Genhai Zhao ${ }^{1}$

Published online: 14 April 2020

(C) Springer-Verlag GmbH Germany, part of Springer Nature 2020

Correction to: Applied Microbiology and Biotechnology https://doi.org/10.1007/s00253-020-10470-w

The online version of the original article can be found at https://doi.org/ 10.1007/s00253-020-10470-w

\footnotetext{
Zhiming Zheng

zhengzhiming2014@163.com

$\triangle$ Genhai Zhao

zhgh327@126.com

1 Key Laboratory of High Magnetic Field and Ion Beam Physical Biology, Hefei Institutes of Physical Science, Chinese Academy of Sciences, 350 Shushanhu Road, Hefei 230031, Anhui, People's Republic of China

2 University of Science and Technology of China, Hefei 230026, Anhui, People's Republic of China
} 
The published online version contains some errors. The correct Fig. 1 is given below. The curve near $\mathrm{X}$ axis in Fig. 2a is numbered ' $a$ ', and others are orderly numbered ' $b-f$ '. 'Five-millimeter' in Fig. 4 legend and corresponding description in Results should be ' 5 $\mathrm{mM}$ '. a

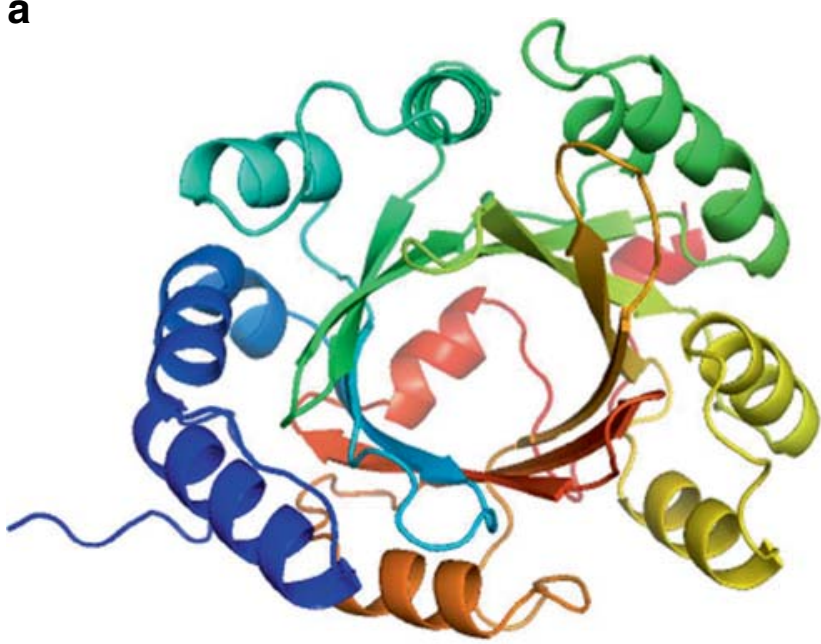

C

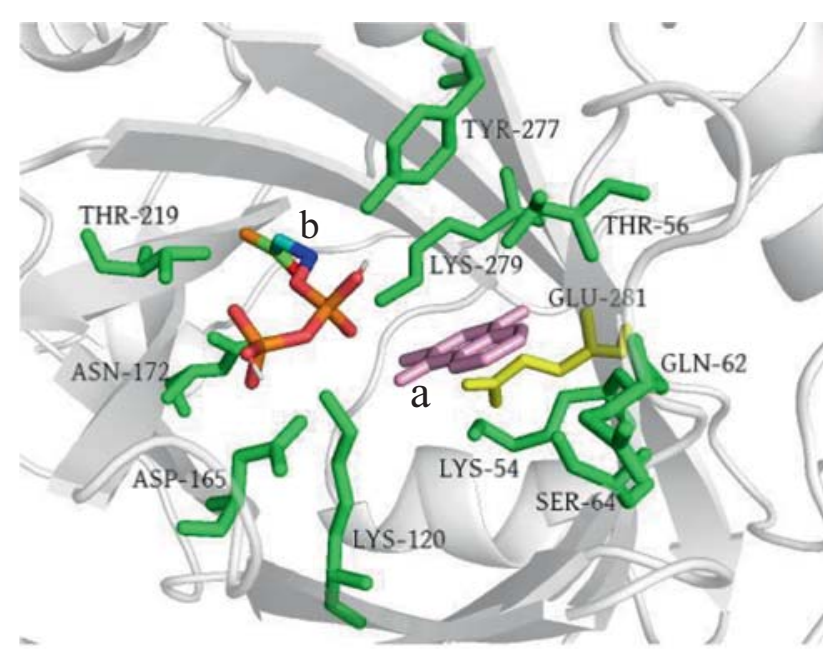

b

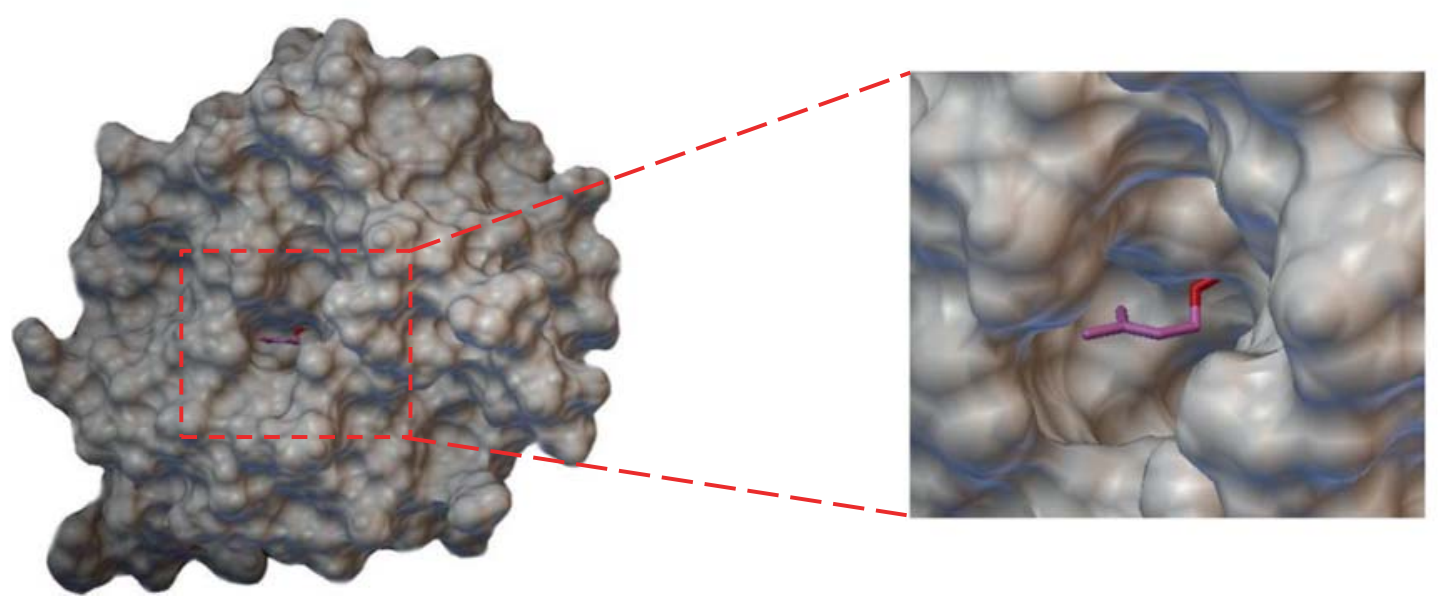

The original article has been corrected.

Publisher's note Springer Nature remains neutral with regard to jurisdictional claims in published maps and institutional affiliations. 